\title{
UPAYA PENINGKATAN HASIL BELAJAR GERAK DASAR LARI DAN LOMPAT MELALUI PERMAINAN TRADISIONAL
}

\author{
Abdul Malik ${ }^{(1)}$ \\ Universitas Sebelas Maret Surakarta
}

\begin{abstract}
The purpose of this study is to improve the learning results of basic motion run and jump through the traditional game in learning pemas on third grade students MIN SROYO Jaten Karanganyar teaching 2016/2017.

This research is a Classroom Action Research (CAR). This study was conducted in two cycles, consisting of four stages in each cycle consisting of planning, action implementation, observation and reflection. Subjects in Action Research This class is the third grade students MIN SROYO Jaten Karanganyar, amounting to 31 students consisting of 16 students and 15 female students. Sources of data in this study come from students, researchers and teachers who act as collaborators. Techniques of collecting data using tests and observations. Data validity using data triangulation technique. Data analysis using qualitative descriptive technique based on qualitative analysis percentage.

Result of research on prasiklus only 11 complete student (35.49\%) and 20 students unfinished $(64,51 \%)$. In the first cycle obtained the results of student learning that has been completed as many as 18 students (58.07\%) and 13 students are not complete (41.93\%). With the acquisition of affective averages (77.42\%), psychomotor (35.49\%) and cognitive (83.87\%). In the second cycle obtained the results of student learning that has been completed as many as 26 students $(83.87 \%)$ and 5 students is not complete (16.13\%). With the acquisition of affective averages (96.77\%), psychomotor (74.19\%) and cognitive (83.87\%) Based on the analysis results from cycle I and cycle II showed a significant increase and target achievement.

Based on the results of the research obtained the conclusion that: The use of simple aids in learning can improve the learning results of basic motion run and jump on the students of class III MIN SROYO Jaten Karanganyar academic year 2016/2017.
\end{abstract}

Keywords: Learning Outcomes, Basic Motion Run And Jump, Traditional Games 
PENDAHULUAN

Pendidikan adalah suatu usaha sadar dalam menyiapkan peserta didik melalui kegiatan bimbingan, pengajaran dan latihan bagi kehidupan yang akan mendatang. Hal ini merupakan tanggung jawab bersama-sama antara pemerintah, anggota masyarakat dan para orangtua. Pembangunan didalam bidang pendidikan adalah upaya yang sangat menentukan dalam rangka meningkatkan kualitas manusia. Salah satu upaya itu adalah mewujudkan insan manusia yang sehat, kuat, terampil dan bermoral melalui pendidikan jasmani. Pendidikan Jasmani, Olahraga dan Kesehatan merupakan bagian dari pendidikan keseluruhan yang mengutamakan aktivitas jasmani dan pembinaan hidup sehat untuk pertumbuhan dan perkembangan jasmani, mental, sosial dan emosional yang serasi, selaras dan seimbang.

Tujuan dari pendidikan jasmani adalah untuk membantu siswa dalam meningkatkan, memperbaiki kesehatan dan kebugaran jasmaninya melalui pengembangan sikap positif dan keterampilan gerak dasar serta sebagai aktifitas jasmani. Oleh karena itu tugas anak menguasai keterampilan gerak dalam berbagai cabang olahraga merupakan tanggung jawab utama dari guru pendidikan jasmani. Selain itu sudah menjadi kesepakatan umum bahwa tujuan pembelajaran melalui program pendidikan jasmani harus pula mencakup peningkatan kebugaran jasmani siswanya.

Proses pembelajaran Pendidikan Jasmani dan Kesehatan di kelas III MI Negeri Sroyo Jaten, ditemukan fakta bahwa siswa kurang berminat mengikuti pembelajaran gerak dasar lari dan lompat karena bukan permainan, mengakibatkan nilai dari pembelajaran gerak dasar lari dan lompat tersebut yang terdapat dalam semester genap kelas III masih belum mencapai KKM yang berlaku di sekolah. Aspek penilaian dari mata pelajaran pendidikan jasmani yang berdasar pada tiga aspek yaitu afektif, kognitif, dan psikomotor juga 
belum dapat dicapai dengan baik.

Berdasarkan hasil observasi dan wawancara yang dilakukan dengan guru penjas sebagai kolaborator hasil belajar, masih banyak siswa yang belum mampu melakukan gerak dasar lari dan lompat dengan benar. Pada saat proses pembelajaran masih banyak siswa cenderung pasif dan kurang bersemangat untuk mengikuti pelajaran gerak dasar lari dan lompat dikarenakan proses pembelajaran tidak menggunakan media dan model pembelajaran yang menarik bahkan siswa masih banyak yang berkeliaran untuk bermain sendiri, disekolah tersebut belum pernah juga dilakukan pembelajaran dengan menggunakan pendekatan bermaian melalui permainan tradisional. Akibat hal-hal tersebut banyak siswa yang belum mampu mencapai nilai standard KKM yaitu nilai 75 , yang belum mencapai KKM 64 \% sehingga dari 31 siswa hanya 11 siswa yang mampu tuntas dan mencapai KKM.

Gerak dasar pada umumnya belum bisa berkembang secara maksimal, sehingga akan berdampak pada tampilan geraknya dalam pembelajaran pendidikan jasmani kurang baik. Gerak dasar lari dan lompat telah dimiliki oleh siswa SD/MI, namun yang menjadi masalah adalah bagaimana cara menanamkan kepada siswa agar bentuk gerakan dasar yang telah dimiliki dapat dilakukan dengan benar. Hal seperti ini harus segera di atasi dengan cara memberikan pembelajaran yang tepat untuk meningkatkan kemampuan gerak dasar siswa.

Dalam hal peningkatan keterampilan gerak dasar lari dan lompat di sekolah dasar terutama peserta didik kelas III akan sangat efektif jika menggunakan pendekatan bermain. Pendekatan permainan merupakan salah satu yang dapat diterapkan untuk mengembangkan kemampuan gerak dasar anak. Untuk dapat mengembangkan kemampuan gerak dasar lari dan lompat anak melalui pendekatan permainan, maka guru penjasorkes harus mampu membuat atau menciptakan permainan yang tepat, untuk meningkat gerak dasar lari dan lompat. Sebagai contoh menggunakan permainan-permainan 
yang akan merangsang keaktifan dan semangat siswa dalam mengikuti pembelajaran salah satunya permainan tradisional.

Permainan tradisional adalah salah sau permainan yang tepat untuk meningkatkan hasil belajar gerak dasar lari dan lompat di sekolah. Melalui permainan tradisional ini siswa akan merasa senang dan tidak bosan mengikuti pembelajaran. Banyak contoh permainan tradisional yang bisa dipakai untuk salah satu cara yang efektif untuk pembelajaran, karena dalam permainan tradisional banyak gerakan yang bagus untuk meningkat gerak dasar siswa.

Berdasarkan beberapa masalah yang dikemukakan diatas mendorong untuk dilkukan solusi yang tepat untuk menyelesaikan masalah yang sedang dihadapi. Dengan maksud agar dapat meningkatkan hasil belajar siswa dalam pembelajaran gerak dasar lari dan lompat. Dari latar belakang yang sudah dipaparkan diatas, perlu diadakan suatu Penelitian Tindakan Kelas (PTK) yaitu, “Upaya Peningkatan Hasil Belajar gerak dasar lari dan lompat melalui permainan tradisional dalam pembelajaran penjas kelas III MI Negeri Sroyo Jaten Karanganyar tahun ajaran 2016/2017".

\section{METODE}

Metode penelitian yang digunakan adalah Penelitian Tindakan Kelas. Subjek yang diteliti dalam Penelitian Tindakan Kelas ini adalah semua siswa kelas III MIN Sroyo Jaten Karanganyar. Jumlah keseluruhan siswa kelas III MIN Sroyo sebanyak 31 siswa.

Teknik pengumpulan data dalam Penelitian Tindakan Kelas ini terdiri atas: tes dan observasi. Tes dipergunakan untuk mendapatkan data tentang hasil belajar gerak dasar lari dan lompat yang dilakukan siswa..

Observasi, digunakan sebagai teknik untuk mengumpulkan data tentang aktivitas siswa selama kegiatan belajar .

\section{HASIL DAN PEMBAHASAN}

Hasil belajar siswa dalam pembelajaran gerak dasar lari dan lompat setelah tindakan siklus II dilakukan menunjukkan hasil bahwa 
yang mencapai kriteria ketuntasan yaitu $83,87 \%$. Sesuai dengan KKM sekolah untuk pendidikan Jasmani di MIN Sroyo Jaten Karanganyar yaitu 75.

Dalam hal ini sejumlah 26 siswa telah masuk dalam kriteria Tuntas sedangkan 5 siswa Tidak Tuntas.

Dalam proses pembelajaran gerak dasar lari dan lompat berjalan baik dan menyenangkan serta siswa tidak takut lagi kakinya sakit dan tidak lagi mengeluh bosan sehingga pembelajaran berjalan efektif dan efisien siswa antusias dalam pembelajaran gerak dasar lari dan lompat sehingga meningkatkan hasil pembelajaran gerak dasar lari dan lompat. Berikut ini masing-masing data jumlah siswa yang tuntas dan prosentase dari setiap penelitian ini.

Pada kondisi awal siswa masih belum memperoleh hasil yang maksimal banyak siswa yang belum sesuai dengan yang diharapkan. Pada pembelajaran siklus 1 terjadi peningkatan dari yang kondisi awal 11 siswa atau 35,49\% menjadi 18 atau 58,07\% tapi ini belum mencapai target yang diharapkan karena banyak siswa yang masih bingung pada permainan ini karena baru sekali mencobanya, sedangkan pada siklus 2 terjadi peningkatan yang sudah melebihi target capaian yaitu 26 atau $83,87 \%$.

Pada siklus 2 sebagian besar siswa mampu melakukan gerak dasar lari dan lompat dengan baik dan benar cuma sedikit siswa yang belum menguasai atau belum melakukan gerak dasar lari dan lompat dengan benar malah ada siswa yang melakukan gerak dasar lari dan lompat dengan baik karenan selain disekolah dirumah anak itu juga melakukan gerakan dasar lari dan lompat hanya beberapa siswa yang belum menguasai gerak dasar lari dan lompat dengan baik dan benar sehingga belum bisa melewati KKM. Siswa juga sangat antusias dan aktif dalam melakukan gerakan-gerakan gerak dasar lari dan lompat karena siswa merasa senang dengan permainan yang digunakan dan sudah tidak merasa kakinya sakit dan mengeluh bosan pada saat pembelajaran.

\section{SIMPULAN DAN SARAN}

Simpulan 
Penelitian Tindakan Kelas

pada Siswa Kelas III MIN Sroyo

Kecamatan Jaten Karanganyar Tahun

Pelajaran 2016/2017 dilaksanakan

dalam dua siklus. Setiap siklus terdiri

atas empat tahapan, yaitu: (1)

perencanaan, (2) pelaksanaan

tindakan, (3) observasi dan

interpretasi, dan (4) analisis dan refleksi.

Dari hasil analisis diperoleh peningkatan yang signifikan dari kondisi awal ke siklus I dan dari siklus I ke siklus II. Hal ini terlihat dari hasil tes unjuk kerja dari studi awal, dari 31 siswa yang pada awalnya mendapatkan ketuntasan 11 siswa $35,49 \%$ dan belum tuntas 20 siswa $64,51 \%$. Pada siklus I, hasil belajar gerak dasar lari dan lompat $55,83 \%$ atau sebanyak 18 siswa dari 31 siswa telah masuk kriteria tuntas. Pada siklus II, hasil belajar siswa meningkat mencapai $83,87 \%$ atau sebanyak 26 siswa dari 31 siswa telah mencapai kriteria tuntas.

Dengan demikian dapat disimpulkan bahwa pembelajaran menggunakan pendekatan bermain yaitu permainan tradisional dapat meningkatkan hasil belajar gerak dasar lari dan lompat pada siswa kelas III MIN Sroyo Kecamatan Jaten Karanganyar Tahun Pelajaran 2016/2017V.

\section{Saran}

Berdasarkan hasil penelitian, maka dapat disarankan beberapa hal, khususnya kepada guru PJOK MIN Sroyo Kecamatan Jaten Karanganyar sebagai berikut :

1. Guru hendaknya terus berusaha untuk meningkatkan kemampuannya dalam mengembangkan materi, menyampaikan materi, serta dalam mengelola kelas, sehingga kualitas pembelajaran yang dilakukannya dapat terus meningkat seiring dengan peningkatan kemampuan yang dimilikinya.

2. Guru hendaknya mau membuka diri untuk menerima berbagai bentuk masukan, saran, dan kritikan dari pihak lain agar dapat lebih memperbaiki kualitas mengajarnya.

3. Kepada guru yang belum menggunakan alat bantu pembelajaran serta belum menerapkan berbagai gaya 


$\begin{array}{lrlr}\text { mengajar atau } \quad \text { metode } & \text { bermain agar dapat } \\ \text { pembelajaran, } & \text { hendaknya } & \text { menyampaikan pembelajaran } \\ \text { mencoba menggunakan berbagai } & \text { dengan tepat dan terarah, } \\ \text { gaya mengajar atau metode } & \text { khususnya pada pembelajaran } \\ \text { mengajar seperti pendekatan } & \text { PJOK. }\end{array}$




\section{DAFTAR PUSTAKA}

Agus Kristiyanto. (2010). Penelitian Tindakan Kelas (PTK) Dalam Pendidikan Jasmani dan Kepelatihan Olahraga. Surakarta: UNS Press

Agus Suprijono. (2009). Cooperative Learning \& Aplikasi PAIKEM. Yogyakarta: Pustaka Pelajar

Ahmad Susanto. (2013).Teori Belajar Pembelajaran. Jakarta:

Prenadamedia

Daryanto. (2013). Media Pembelajaran. Yogyakarta: Gava Media

Diah Rahmawati \& Rosalia. (2016). Aku Pintar Dengan Bermain. Solo: Metagraf Tiga Serangkai

Dikdik Zafar. (2013). Mengajar dan Melatih Atletik. Bandung: Remaja Rosdakarya

Endang Komara. (2014). Belajar Dan Pembelajaran Interaktif. Bandung: PT Rafika Aditama

Giri Wiarto. (2013). Atletik. Yogyakarta: Graha Ilmu

Hamdani. (2011). Strategi Belajar Mengajar. Bandung: Pustaka Setia

Harry ricketts. (2012). Sport New Zealand. London: Awapress

Heru Rahyubi. (2012). Teori-Teori Belajar dan Aplikasi Pembelajaran Motorik. Jakarta: Nusapedia

Jamil Suprihatiningrum. (2012). Strategi Pembelajaran Teori dan Aplikasi. Yogyakarta: AR-RUZZ MEDIA

Khanifatul. (2013). Pembelajaran Inovatif. Yogyakarta: AR-RUZZ MEDIA

Novi Mulyani. (2016). Permainan Tradisional. Yogyakarta: Antini

Purwanto. (2013). Evaluasi Hasil Belajar. Yogyakarta: Pustaka Belajar 